Pacific Journal of Mathematics

TARTAN SUBALGEBRAS OF A LIE ALGEBRA AND ITS 


\title{
CARTAN SUBALGEBRAS OF A LIE ALGEBRA AND ITS IDEALS
}

\author{
DAVID J. WINTER
}

The purpose of this paper is to describe, under suitable conditions which are always satisfied at characteristic 0 , a close relationship between Cartan subalgebras of a Lie algebra $\mathscr{L}$ and Cartan subalgebras of an ideal $\mathscr{L}^{\prime}$ of $\mathscr{L}$. Under the conditions referred to, a mapping $\alpha^{*}$ from the set of Cartan subalgebras of $\mathscr{L}$ onto the set of Cartan subalgebras of $\mathscr{L}^{\prime}$ is described and the fibres of $\alpha^{*}$ are determined.

The main tools for the paper are N. Jacobson's generalization of Engel's Theorem [2; p. 33], and Theorem 5 of [4] which deals with Cartan subalgebras of the Fitting zero space of a derivation of a Lie algebra $\mathscr{L}$. In addition, general material on Lie algebras, to be found in [2], [3], is presupposed.

Throughout this paper, Lie algebras and vector spaces are finite dimensional.

If $V$ is an $\mathscr{N}$-module where $\mathscr{N}$ is a nilpotent Lie algebra over the field $F$, the null and one components of $V$ are denoted $V_{0}(\mathscr{N})$, $V_{*}\left(\mathscr{N}^{2}\right)$ respectively [cf. 2 ; pp. 37-43] and, for $\alpha$ a function from $\mathscr{N}$ into $F, V_{\alpha}(\mathscr{N})=\left\{v \in V \mid v(I-\alpha(x))^{\operatorname{dim} V}=0\right.$ for all $\left.x \in \mathscr{N}\right\}$.

If $V$ is a vector space (respectively Lie algebra, respectively module for a Lie algebra, over $F$, then the extension $V \otimes_{F} K$ of $V$ to an extension field $K$ of $F$ is denoted $V_{K}$.

2. Cartan subalgebras of a Lie algebra and its ideals. Throughout this section, $\mathscr{L}$ denotes a Lie algebra over an arbitrary field $F$. The characteristic of $F$ is denoted $p, p=0$ being permissible. Let $\mathscr{L}^{\prime}$ be an ideal of $\mathscr{L}$ and let the canonical short exact sequence determined by $\mathscr{L}, \mathscr{L}^{\prime}$ be denoted

$$
0 \longrightarrow \mathscr{L}^{\prime} \stackrel{\alpha}{\longrightarrow} \mathscr{L} \stackrel{\beta}{\longrightarrow} \overline{\mathscr{L}}=\mathscr{L} \mid \mathscr{L}^{\prime} \longrightarrow 0 \text {, }
$$

where $\alpha$ is the inclusion mapping. The set of Cartan subalgebras of $\mathscr{L}$ is denoted Cart $\mathscr{L}$. For $\mathscr{H} \in \operatorname{Cart} \mathscr{L},\left(\mathscr{L}^{\prime}\right)_{0}\left(\right.$ ad $\left.\left(\mathscr{H} \cap \mathscr{L}^{\prime}\right)\right)$ is denoted $\alpha^{*}(\mathscr{H})$. Our main objective is to prove the following theorem.

THEOREM. Suppose that either $p=0$, or $p \neq 0$ and $\left(\operatorname{ad}_{\mathscr{L}} \mathscr{L}^{\prime}\right)^{p} \subset$ $\operatorname{ad}_{\mathscr{E}}, \mathscr{L}^{\prime}$ and $\left(\operatorname{ad}_{\mathscr{L}} \mathscr{L}\right)^{p} \subset \operatorname{ad}_{\mathscr{L}} \mathscr{L}$. Then $\alpha^{*}($ Cart $\mathscr{L})=$ Cart $\mathscr{L}^{\prime}$ and 
$\alpha^{*-1}\left(\mathscr{H}^{\prime}\right)=\operatorname{Cart} \mathscr{L}_{0}\left(\operatorname{ad} \mathscr{H}^{\prime}\right)$ for $\mathscr{H}^{\prime} \in \operatorname{Cart} \mathscr{L}^{\prime}$.

We defer the proof for the moment, since it is convenient to have the following lemma at our disposal.

Lemma. Let $V$ be a vector space over $F$, $\mathscr{L}$ a Lie subalgebra of $\mathrm{Hom}_{F} V$. If the characteristic of $F$ is $p \neq 0$, suppose that $\mathscr{L}$ is closed under $p$-th powers. Let $\mathscr{N}$ be a nilpotent subalgebra of $\operatorname{Hom}_{F} V$ which normalizes $\mathscr{L}$. Suppose that $\mathscr{L}_{0}(\mathrm{ad} \mathscr{N})$ consists of nilpotent transformations of $V$. Then $\mathscr{L}$ consists of nilpotent transformations of $V$.

Proof of lemma. Since $\mathscr{L}_{0}(\mathrm{ad} \mathscr{N})$ consists of nilpotent transformations and is closed under brackets, $\mathscr{L}_{0}(\operatorname{ad} \mathscr{N})_{K}=\left(\mathscr{L}_{K}\right)_{0}\left(\operatorname{ad} \mathscr{N}_{K}\right)$ consists of nilpotent transformations where $K$ is the algebraic closure of $F$. Moreover, if the characteristic of $F$ is $p \neq 0, \mathscr{L}_{K}$ is closed under $p$-th powers [cf. 2; p. 190]. Thus, we may assume without loss of generality that $F$ is algebraically closed.

Now $\mathscr{L}=\sum \mathscr{L}_{\alpha}($ ad $\mathscr{N})$ and $V=\sum V_{\beta}(\mathscr{N})$. For all $\alpha, \beta$, we have $V_{\beta}(\mathscr{N}) \mathscr{L}_{\alpha}($ ad $\mathscr{N}) \subset V_{\beta+\alpha \text { oad }}(\mathscr{N})$ [cf. 2; p. 63]. Thus, if the characteristic of $F$ is $0, \mathscr{L}_{\alpha}($ ad $\mathscr{N})$ consists of nilpotent transformations for all $\alpha$ : for $\alpha=0$ by hypothesis and for $\alpha \neq 0$ by the above observation. Suppose next that the characteristic of $F$ is $p \neq 0$. Let $x \in L_{\alpha}(\operatorname{ad} \mathscr{N})$. Then $x^{p} \in \mathscr{L} \cap\left(\operatorname{Hom}_{F} V\right)_{0}(\operatorname{ad} \mathscr{N})=\mathscr{L}_{0}(\operatorname{ad} \mathscr{N})$, for if $t$ is the semi-simple part of an element $y$ of $\mathscr{N}, t$ ad $x=-\alpha(y) x$ so that $0=t(\operatorname{ad} x)^{2}=\cdots=t(\operatorname{ad} x)^{p}=\left[t, x^{p}\right]$. Thus, $x^{p}$, hence $x$, is nilpotent. Thus, the $\mathscr{L}_{\alpha}($ ad $\mathscr{N})$ again consist of nilpotent transformations for all $\alpha$. We now can apply [2; p. 33] to the weakly closed set $\cup \mathscr{L}_{\alpha}(\mathrm{ad} \mathscr{N})$ of nilpotent transformations. This implies that the Lie algebra generated by $\cup \mathscr{L}_{\alpha}($ ad $\mathscr{N})$, namely $\mathscr{L}$ itself, consists of nilpotent transformations.

Proof of theorem. We first show that $\alpha^{*}(\operatorname{Cart} \mathscr{L}) \subset$ Cart $\mathscr{L}^{\prime}$. Thus, let, $\mathscr{H} \in$ Cart $\mathscr{L}$. Then $\mathscr{H} \cap \mathscr{L}^{\prime}=\mathscr{L}_{0}($ ad $\mathscr{H}) \cap \mathscr{L}^{\prime}=\left(\mathscr{L}^{\prime}\right)_{0}($ ad $\mathscr{H})$. Now $\mathscr{N}=$ ad $\left.\mathscr{C}\right|_{\mathscr{L}}$ is a nilpotent Lie algebra of derivations of $\mathscr{L}^{\prime}$ and $\mathscr{H} \cap \mathscr{L}^{\prime}$ is trivially a Cartan subalgebra of $\left(\mathscr{L}^{\prime}\right)_{0}(\mathscr{N})=\mathscr{H} \cap \mathscr{L}^{\prime}$. Thus, Theorem 5 of [4] applies and shows that $\left(\mathscr{L}^{\prime}\right)_{0}\left(\operatorname{ad}\left(\mathscr{H} \cap \mathscr{L}^{\prime}\right)\right)=$ $\alpha^{*}(\mathscr{L})$ is a Cartan subalgebra of $\mathscr{L}^{\prime}$.

Next suppose that $\mathscr{H}^{\prime} \in$ Cart $\mathscr{L}^{\prime}$ and that $\mathscr{N} \in \operatorname{Cart} \mathscr{L}_{0}\left(\right.$ ad $\left.\mathscr{X}^{\prime}\right)$. Since $\mathscr{L}_{0}\left(\right.$ ad $\left.\mathscr{C}^{\prime}\right)$ normalizes $\mathscr{L}_{0}\left(\operatorname{ad} \mathscr{H}^{\prime}\right) \cap \mathscr{L}^{\prime}=\left(\mathscr{L}^{\prime}\right)_{0}\left(\right.$ ad $\left.\mathscr{C}^{\prime}\right)=\mathscr{H}^{\prime}$, we have:

$$
\mathscr{N} \text { normalizes } \mathscr{H}^{\prime} \text {. }
$$

In view of (1), we have $\mathscr{H}^{\prime}=\mathscr{C}_{0}^{\prime} \oplus \mathscr{H}_{*}^{\prime}$ where $\mathscr{C}_{0}^{\prime}=\left(\mathscr{H}^{\prime}\right)_{0}(\operatorname{ad} \mathscr{N})$ 
and $\mathscr{H}_{*}^{\prime}=\left(\mathscr{H}^{\prime}\right)_{*}($ ad $\mathscr{N})$. Note that $\mathscr{H}_{0}^{\prime}=\mathscr{H}^{\prime} \cap \mathscr{N}$ since $\mathscr{N} \in$ Cart $\mathscr{L}_{0}\left(\right.$ ad $\left.\mathscr{H}^{\prime}\right)$ and $\mathscr{H}^{\prime} \subset \mathscr{L}_{0}\left(\right.$ ad $\left.\mathscr{H}^{\prime}\right)$. Let $V=\left(\mathscr{L}^{\prime}\right)_{0}\left(\right.$ ad $\left.\mathscr{H}_{0}^{\prime}\right)$. Since $\mathscr{H}_{0}^{\prime} \subset \mathscr{H}^{\prime}$ and $\mathscr{H}_{0}^{\prime} \subset \mathscr{N}, V$ is stable under ad $\mathscr{H}^{\prime}$ and ad $\mathscr{N}$ [cf. $2 ;$ p. 58]. Now we prepare the way for applying the above lemma to $\left(V\right.$, ad $\left.\mathscr{H}^{\prime}\right|_{V}$, ad $\left.\left.\mathscr{N}\right|_{V}\right)$. Thus, note that ad $\left.\mathscr{H}^{\prime}\right|_{V}$ is a subalgebra of $\operatorname{Hom}_{F} V$ normalized by the nilpotent subalgebra ad $\left.\mathscr{N}\right|_{V}$ and that, if the characteristic of $F$ is $p \neq 0$, ad $\left.\mathscr{H}^{\prime}\right|_{V}$ is closed under $p$-th powers. (In fact, $\operatorname{ad}_{\mathscr{L}^{\prime}}, \mathscr{Z}^{\prime}$ is closed under $p$-th powers since $\operatorname{ad}_{L^{\prime}} \mathscr{L}^{\prime}$ is closed under $p$-th powers and since $\mathscr{C}^{\prime}$ is a Cartan subalgebra of $\mathscr{L}^{\prime}$ : for $x \in \mathscr{H}^{\prime},(\operatorname{ad} x)^{p}=$ ad $y$ for some $y \in \mathscr{L}^{\prime}$, and $y \in \mathscr{H}^{\prime}$, since $\left.\mathscr{C} \supset \mathscr{C}(\operatorname{ad} x)^{p}=[\mathscr{H}, y]\right)$. Moreover

$$
\left(\left.\operatorname{ad} \mathscr{H}^{\prime}\right|_{V}\right)_{0}\left(\operatorname{ad}\left(\left.\operatorname{ad} \mathscr{N}\right|_{V}\right)\right)=\left.\operatorname{ad} \mathscr{C}_{0}^{\prime}\right|_{V}
$$

and ad $\left.\mathscr{L}_{0}^{\prime}\right|_{V}$ consists of nilpotent transformations by the definition of $V$. Thus, by the lemma, ad $\left.\mathscr{H}^{\prime}\right|_{V}$ consists of nilpotent transformations. Thus, $\left(\mathscr{L}^{\prime}\right)_{0}\left(\right.$ ad $\left.\mathscr{H}_{0}^{\prime}\right)=\left(\left(\mathscr{L}^{\prime}\right)_{0}\left(\right.\right.$ ad $\left.\mathscr{L}^{\prime}\right)=\mathscr{H}^{\prime}$. We therefore have:

$$
\mathscr{C}^{\prime}=\left(\mathscr{L}^{\prime}\right)_{0}\left(\operatorname{ad}\left(\mathscr{H}^{\prime} \cap \mathscr{N}^{\prime}\right)\right) .
$$

We show that (2) implies $\mathscr{L}^{\prime}=\left(\mathscr{L}^{\prime}\right)_{0}($ ad $(\mathscr{L} \cap \mathscr{L}))$ for substable $\mathscr{H} \in \operatorname{Cart} \mathscr{L}$. Thus, let $\mathscr{H}=\mathscr{L}_{0}(\operatorname{ad} \mathscr{N})$. Then $\mathscr{H} \in$ Cart $\mathscr{L}$, by Theorem 5 of [4], since $\mathscr{N}$ is a Cartan subalgebra of $\mathscr{L}_{0}\left(\operatorname{ad} \mathscr{C}^{\prime}\right)$. Since $\mathscr{H}^{\prime} \cap \mathscr{N} \subset \mathscr{L}^{\prime} \cap \mathscr{H}$, (2) implies that

$$
\alpha^{*}(\mathscr{H})=\left(\mathscr{L}^{\prime}\right)_{0}\left(\operatorname{ad}\left(\mathscr{L}^{\prime} \cap \mathscr{L}\right)\right) \subset\left(\mathscr{L}^{\prime}\right)_{0}\left(\operatorname{ad}\left(\mathscr{C}^{\prime} \cap \mathscr{N}\right)\right)=\mathscr{H}^{\prime} .
$$

Thus, since $\alpha^{*}(\mathscr{C}) \in$ Cart $\mathscr{L}^{\prime}$, by the preceding paragraph, $\alpha^{*}(\mathscr{C})=$ $\mathscr{C}^{\prime}$, by the maximal nilpotency of Cartan subalgebras. Thus, we have:

$$
\mathscr{L}_{0}(\operatorname{ad} \mathscr{N}) \in \operatorname{Cart} \mathscr{L} \text { and } \alpha^{*}\left(\mathscr{L}_{0}(\operatorname{ad} \mathscr{N})\right)=\mathscr{L}^{\prime} .
$$

We have $\alpha^{*}($ Cart $\mathscr{L}) \subset$ Cart $\mathscr{C}^{\prime}$, from the first paragraph. Thus, it follows from (3) that $\alpha^{*}($ Cart $\mathscr{L})=$ Cart $\mathscr{L}^{\prime}$. Note, however, that the existence of $\mathscr{N} \in$ Cart $\mathscr{L}_{0}\left(\right.$ ad $\left.\mathscr{C}^{\prime}\right)$ is used for this conclusion. But ad $\mathscr{L}_{0}\left(\right.$ ad $\left.\mathscr{C}^{\prime}\right)$ is a linear Lie $p$-algebra for $p \neq 0$, as the null component of the linear Lie $p$-algebra ad $\mathscr{L}$ with respect to the subalgebra ad $\mathscr{H}^{\prime}$. Thus, ad $\mathscr{L}_{0}\left(\right.$ ad $\left.\mathscr{L}^{\prime}\right)$ has a Cartan subalgebra, by $\left[3 ;\right.$ p. 121], so that $\mathscr{L}_{0}\left(\right.$ ad $\left.\mathscr{H}^{\prime}\right)$ has a Cartan subalgebra.

Finally, we suppose that $\mathscr{H}^{\prime} \in \operatorname{Cart} \mathscr{L}^{\prime}$. Let $\mathscr{\mathscr { C }} \in \alpha^{*-1}\left(\mathscr{C}^{\prime}\right)$. Then $\mathscr{H} \subset \mathscr{L}_{0}\left(\right.$ ad $\left.\left(\mathscr{H} \cap \mathscr{L}^{\prime}\right)\right)$, so that $\mathscr{C}$ normalizes

$$
\mathscr{H}^{\prime}=\mathscr{L}_{0}\left(\operatorname{ad}\left(\mathscr{H} \cap \mathscr{L}^{\prime}\right)\right) \cap \mathscr{L}^{\prime} \text {. }
$$

Thus, $\mathscr{H} \subset \mathscr{L}_{0}\left(\operatorname{ad} \mathscr{H}^{\prime}\right)$, so that $\mathscr{H} \in \operatorname{Cart} \mathscr{L}_{0}\left(\right.$ ad $\left.\mathscr{H}^{\prime}\right)$. Suppose, conversely, that $\mathscr{N} \in \operatorname{Cart} \mathscr{L}_{0}\left(\right.$ ad $\left.\mathscr{L}^{\prime}\right)$. By $(3), \mathscr{L}_{0}($ ad $\mathscr{N}) \in \operatorname{Cart} \mathscr{L}$ 
and $\alpha^{*}\left(\mathscr{L}_{0}(\operatorname{ad} \mathscr{N})\right)=\mathscr{H}^{\prime}$. Thus, by first part of this paragraph, $\mathscr{L}_{0}(\operatorname{ad} \mathscr{N}) \subset \mathscr{L}_{0}\left(\operatorname{ad} \mathscr{H}^{\prime}\right)$. But then

$$
\left.\mathscr{L}_{0}(\operatorname{ad} \mathscr{N})=\mathscr{L}_{0}\left(\operatorname{ad} \mathscr{H}^{\prime}\right)\right)_{0}(\operatorname{ad} \mathscr{N})=\mathscr{N},
$$

since $\mathscr{N} \in \operatorname{Cart} \mathscr{L}_{0}\left(\operatorname{ad} \mathscr{C}^{\prime}\right)$ [cf. 2; p. 57-58]. Thus, $\mathscr{N}$ is a Cartan subalgebra of $\mathscr{L}$, by [2; p. 57-58]. Now

$$
\alpha^{*}(\mathscr{N})=\alpha^{*}\left(\mathscr{L}_{\mathrm{c}}(\operatorname{ad} \mathscr{N})\right)=\mathscr{H}^{\prime},
$$

by (3), and $\mathscr{N} \in \alpha^{*^{-1}}\left(\mathscr{H}^{\prime}\right)$. Thus, $\alpha^{*-1}\left(\mathscr{H}^{\prime}\right)=$ Cart $\mathscr{L}_{0}\left(\operatorname{ad} \mathscr{H}^{\prime}\right)$.

We now turn to two related results. The first is concerned with the fibres of $\alpha^{*}$. The second is concerned with the relations between the sequences

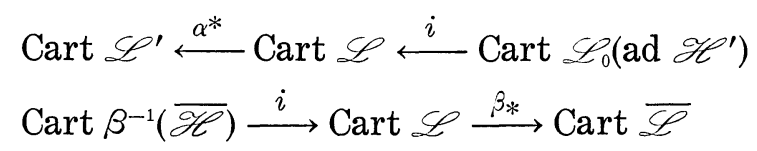

where $i$ is inclusion, $\mathscr{H} \in \operatorname{Cart} \mathscr{L}, \mathscr{H}^{\prime}=\alpha^{*}(\mathscr{H}), \overline{\mathscr{H}}=\beta(\mathscr{H})$ and $\beta_{*}$ is defined by $\beta_{*}(\mathscr{J})=\beta(\mathscr{J})$ for $\mathscr{J} \in \operatorname{Cart} \mathscr{L}$.

Proposition 1. Let the hypothesis be as in the theorem, and let $\mathscr{H} \in$ Cart $\mathscr{L}, \mathscr{L}^{\prime} \in$ Cart $\mathscr{L}^{\prime}$. Then the following conditions are equivalent.

(1) $\mathscr{H}^{\prime}=\alpha^{*}(\mathscr{H})$;

(2) $\mathscr{H}$ normalizes $\mathscr{H}^{\prime}$;

(3) $\mathscr{H} \cap \mathscr{L}^{\prime} \subset \mathscr{H}^{\prime}$.

Proof. If $\mathscr{H}^{\prime}=\alpha^{*}(\mathscr{H})$, then $\mathscr{H} \subset \mathscr{L}_{0}\left(\operatorname{ad}\left(\mathscr{L}^{\prime} \cap \mathscr{H}\right)\right)$ and $\mathscr{H}$ normalizes $\mathscr{H}^{\prime}=\mathscr{L}_{0}\left(\operatorname{ad}\left(\mathscr{L}^{\prime} \cap \mathscr{H}\right)\right) \cap \mathscr{L}^{\prime}$. Thus, (1) implies (2). If $\mathscr{H}$ normalizes $\mathscr{H}^{\prime}$, then $\mathscr{H} \subset \mathscr{L}_{0}\left(\operatorname{ad} \mathscr{H}^{\prime}\right)$ and

$$
\mathscr{H} \cap \mathscr{L}^{\prime} \subset\left(\mathscr{L}^{\prime}\right)_{0}\left(\text { ad } \mathscr{H}^{\prime}\right)=\mathscr{H}^{\prime} \text {. }
$$

Thus, (2) implies (3). Suppose, finally, that $\mathscr{H} \cap \mathscr{L}^{\prime} \subset \mathscr{H}^{\prime}$. Then $\mathscr{H}^{\prime}=\left(\mathscr{L}^{\prime}\right)_{0}\left(\right.$ ad $\left.\mathscr{H}^{\prime}\right) \subset\left(\mathscr{L}^{\prime}\right)_{0}\left(\operatorname{ad}\left(\mathscr{H} \cap \mathscr{L}^{\prime}\right)\right)=\alpha^{*}(\mathscr{H})$. But $\alpha^{*}(\mathscr{H}) \epsilon$ Cart $\mathscr{L}^{\prime}$ and $\mathscr{H}^{\prime}$ is, a Cartan subalgebra of $\mathscr{L}^{\prime}$, maximal nilpotent in $\mathscr{L}^{\prime}$. Thus, $\mathscr{H}^{\prime}=\mathscr{L}(\mathscr{H})^{*}(\mathscr{H})$. Thus (3) implies (1), and the conditions (1)-(3) are equivalent.

Proposition 2. Let the hypothesis be as in the theorem. Let $\mathscr{H} \in \operatorname{Cart} \mathscr{L}, \mathscr{H}^{\prime}=\alpha^{*}(\mathscr{H}), \overline{\mathscr{H}}=\beta(\mathscr{H})$. Then $\mathscr{H}$ normalizes $\mathscr{H}^{\prime}$, Cart $\mathscr{L}$ contains $\operatorname{Cart}\left(\mathscr{H}+\mathscr{H}^{\prime}\right)$, Cart $\mathscr{L}_{0}\left(\operatorname{ad} \mathscr{H}^{\prime}\right)$ and $\operatorname{Cart} \beta^{-1}(\overline{\mathscr{C}})$, and $\left(\operatorname{Cart} \mathscr{L}_{0}\left(\operatorname{ad} \mathscr{H}^{\prime}\right)\right) \cap \operatorname{Cart} \beta^{-1}(\overline{\mathscr{H}})=\operatorname{Cart}\left(\mathscr{H}+\mathscr{H}^{\prime}\right)$.

Proof. $\mathscr{H}$ normalizes $\mathscr{H}^{\prime}$, by Proposition 1. Since 


$$
\beta^{-1}(\overline{\mathscr{C}})=\mathscr{H}+\mathscr{S}^{\prime}, \mathscr{L}_{0}\left(\operatorname{ad} \mathscr{C}^{\prime}\right) \cap \beta^{-1}(\overline{\mathscr{C}})=\mathscr{H}+\mathscr{H}^{\prime} .
$$

Thus, it suffices to show that Cart $\mathscr{L}$ contains Cart $\mathscr{L}_{0}\left(\operatorname{ad} \mathscr{L}^{\prime}\right)$, $\operatorname{Cart} \beta^{-1}(\overline{\mathscr{C}})$ and $\operatorname{Cart}\left(\mathscr{H}+\mathscr{H}^{\prime}\right)$. The first two sets are contained in Cart $\mathscr{L}$ - Cart $\mathscr{L}_{0}\left(\right.$ ad $\left.\mathscr{C}^{\prime}\right)$ by the theorem and $\operatorname{Cart} \beta^{-1}(\overline{\mathscr{C}})$ by [1]. Thus, it remains only to show that

$$
\operatorname{Cart}\left(\mathscr{H}+\mathscr{K}^{\prime}\right) \subset \operatorname{Cart} \mathscr{L}_{0}\left(\operatorname{ad} \mathscr{C}^{\prime}\right) \text {. }
$$

But $\mathscr{H}^{\prime}=\mathscr{L}_{0}\left(\operatorname{ad} \mathscr{H}^{\prime}\right) \cap \mathscr{L}^{\prime}$ is an ideal of $\mathscr{L}_{0}\left(\operatorname{ad} \mathscr{C}^{\prime}\right)$ and $\mathscr{H} \in$ Cart $\mathscr{L}_{0}\left(\operatorname{ad} \mathscr{C}^{\prime}\right)$. Thus, Cart $\left(\mathscr{C}+\mathscr{H}^{\prime}\right) \subset$ Cart $\mathscr{K}_{0}\left(\right.$ ad $\left.\mathscr{C}^{\prime}\right)$, by [1], since $\mathscr{H}+\mathscr{H}^{\prime}$ is the preimage in $\mathscr{L}_{0}\left(\right.$ ad $\left.\mathscr{H}^{\prime}\right)$ of the Cartan subalgebra $\left(\mathscr{H}+\mathscr{H}^{\prime}\right) / \mathscr{H}^{\prime}$ of $\mathscr{L}_{0}\left(\right.$ ad $\left.\mathscr{H}^{\prime}\right) / \mathscr{H}^{\prime}$.

\section{REFERENCES}

1. D. W. Barnes, On Cartan subalgebras of Lie algebras, Math. Zeit. 101 (1967), 350355 .

2. N. Jacobson, Lie algebras, Interscience, New York, 1962.

3. G. Seligman, Modular Lie algebras, Springer, New York, 1967.

4. D. J. Winter, On groups of automorphisms of Lie algebras, J. of Algebra 8 (1968).

Received February 11, 1969. This research was done while the author was a National Science Foundation Postdoctoral Fellow at the University of Bonn.

UNIVERSITY OF BONN

UNIVERSITY OF MICHIGAN 



\section{PACIFIC JOURNAL OF MATHEMATICS}

\section{EDITORS}

H. SAMelson

Stanford University

Stanford, California 94305

\section{Richard PIERCE}

University of Washington

Seattle, Washington 98105
J. DugundjI

Department of Mathematics

University of Southern California

Los Angeles, California 90007

BASIL GoRDON*

University of California

Los Angeles, California 90024

\section{ASSOCIATE EDITORS}
E. F. BECKENBACH
B. H. NeumanN
F. WOLE
K. YosHIDA

\section{SUPPORTING INSTITUTIONS}

UNIVERSITY OF BRITISH COLUMBIA

CALIFORNIA INSTITUTE OF TECHNOLOGY

UNIVERSITY OF CALIFORNIA

MONTANA STATE UNIVERSITY

UNIVERSITY OF NEVADA

NEW MEXICO STATE UNIVERSITY

OREGON STATE UNIVERSITY

UNIVERSITY OF OREGON

OSAKA UNIVERSITY

UNIVERSITY OF SOUTHERN CALIFORNIA

\author{
STANFORD UNIVERSITY \\ UNIVERSITY OF TOKYO \\ UNIVERSITY OF UTAH \\ WASHINGTON STATE UNIVERSITY \\ UNIVERSITY OF WASHINGTON \\ * * * * \\ AMERICAN MATHEMATICAL SOCIETY \\ CHEVRON RESEARCH CORPORATION \\ TRW SYSTEMS \\ NAVAL WEAPONS CENTER
}

The Supporting Institutions listed above contribute to the cost of publication of this Journal, but they are not owners or publishers and have no responsibility for its content or policies.

Mathematical papers intended for publication in the Pacific Journal of Mathematics should be in typed form or offset-reproduced, (not dittoed), double spaced with large margins. Underline Greek letters in red, German in green, and script in blue. The first paragraph or two must be capable of being used separately as a synopsis of the entire paper. The editorial "we" must not be used in the synopsis, and items of the bibliography should not be cited there unless absolutely necessary, in which case they must be identified by author and Journal, rather than by item number. Manuscripts, in duplicate if possible, may be sent to any one of the four editors. Please classify according to the scheme of Math. Rev. 36, 1539-1546. All other communications to the editors should be addressed to the managing editor, Richard Arens, University of California, Los Angeles, California, 90024.

50 reprints are provided free for each article; additional copies may be obtained at cost in multiples of 50 .

The Pacific Journal of Mathematics is published monthly. Effective with Volume 16 the price per volume (3 numbers) is $\$ 8.00$; single issues, $\$ 3.00$. Special price for current issues to individual faculty members of supporting institutions and to individual members of the American Mathematical Society: $\$ 4.00$ per volume; single issues $\$ 1.50$. Back numbers are available.

Subscriptions, orders for back numbers, and changes of address should be sent to Pacific Journal of Mathematics, 103 Highland Boulevard, Berkeley, California, 94708.

PUBLISHED BY PACIFIC JOURNAL OF MATHEMATICS, A NON-PROFIT CORPORATION

Printed at Kokusai Bunken Insatsusha (International Academic Printing Co., Ltd.), 7-17, Fujimi 2-chome, Chiyoda-ku, Tokyo, Japan.

* Acting Managing Editor. 


\section{Pacific Journal of Mathematics}

\section{Vol. 33, No. $2 \quad$ April, 1970}

Raymond Balbes and Alfred Horn, Projective distributive lattices ....... 273

John Findley Berglund, On extending almost periodic functions ......... 281

Günter Krause, Admissible modules and a characterization of reduced left

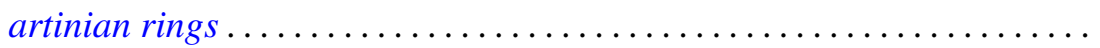

Edward Milton Landesman and Alan Cecil Lazer, Linear eigenvalues and a nonlinear boundary value problem ....................... 311

Anthony To-Ming Lau, Extremely amenable algebras ............... 329

Aldo Joram Lazar, Sections and subsets of simplexes .............. 337

Vincent Mancuso, Mesocompactness and related properties ............. 345

Edwin Leroy Marsden, Jr., The commutator and solvability in a generalized orthomodular lattice .................................. 357

Shozo Matsuura, Bergman kernel functions and the three types of canonical domains.......................................... 363

S. Mukhoti, Theorems on Cesàro summability of series .............. 385

Ngô Van Quê, Classes de Chern et théorème de Gauss-Bonnet ........... 393

Ralph Tyrrell Rockafellar, Generalized Hamiltonian equations for convex problems of Lagrange ................................ 411

Ken iti Sato, On dispersive operators in Banach lattices ............. 429

Charles Andrew Swanson, Comparison theorems for elliptic differential

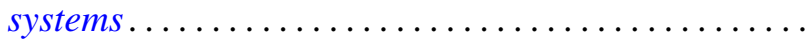

John Griggs Thompson, Nonsolvable finite groups all of whose local subgroups are solvable. II

David J. Winter, Cartan subalgebras of a Lie algebra and its ideals ... 